\title{
A Unified Framework for Using Micro-Data to Compare Dynamic Wage and Price Setting Models
}

\author{
Huw David Dixon
}

\author{
CESIFO WORKING PAPER NO. 3093 \\ CATEGORY 7: MONETARY POLICY AND INTERNATIONAL FINANCE \\ JUNE 2010
}
An electronic version of the paper may be downloaded
- from the SSRN website: www.SSRN.com
- from the RePEc website: - from the CESifo website:




\title{
A Unified Framework for Using Micro-Data to Compare Dynamic Wage and Price Setting Models
}

\begin{abstract}
This paper develops a statistical framework of steady-state identities which enable us to match the distributions of durations found in the micro-data to generalized Taylor and Calvo models of time-dependent pricing. We illustrate the approach with the UK micro CPI data for 2006-2009, and employ the pricing models in a simple macromodel. We find that the Generalized Taylor Economy generates a hump shaped response function, whilst the Generalized Calvo does not.
\end{abstract}

JEL-Code: E50.

Keywords: price-spell, steady state, hazard rate, Calvo, Taylor.

Huw David Dixon

Cardiff Business School

Colum Drive

UK - Cardiff CF10 3EU

dixonh@cardiff.ac.uk

June 8, 2010

This research began when I was a visitor to the ECB in January 2002 and is a revised version of ECB working paper 676 (2006). The financial assistance of the Foundation Banque de France helped me in preparing this revision. I would like to thank Michael Beenstock, Vitor Gaspar, Jurgen von Hagen, Benoit Mojon, Herve Le Bihan, Henri Pages, Adam Reiff, Luigi Siciliani, Peter N Smith, John B Taylor, John Treble and Mike Wickens for helpful clues in my quest. Thanks also to PhD students at York, Cardiff and Lisbon for their comments when I have given this as part of a $\mathrm{PhD}$ course on monetary policy over the last 5 years. The paper has been given at seminars at York, Cardiff, the ECB, Banque de France, and the MMF conference (2006) and European Monetary Forum (2008). I would like to thank Kun Tian and Peng Zhou for estimating the Hazard function, and Yue Jiang for running the policy simulations. I have only myself to blame for any remaining faults. 


\section{Introduction.}

Dynamic pricing and wage-setting models have become central to macroeconomic modelling in the new neoclassical synthesis approach. It has become apparent that different models of pricing have different implications for matters such as the persistence of output and inflation to monetary shocks. Different models of wage or price setting imply different distributions of durations of price-spells (throughout this paper, we will use "price" as a shorthand for "wage and price"). In this paper we focus on the class of time or duration dependent models of pricing, such as Calvo and Taylor, rather than state-dependent models (Dotsey et al 1999, John and Wolman 2008). We formulate a unified framework for consistently understanding and comparing these models.

We start from the idea of modelling the class of all steady state distributions of durations across a given population (in this case, the firms that set prices). In steady state there are four equivalent ways of describing this. First, there is the distribution of durations: this treats each price-spell as an individual element in the population and ignores the fact that price-spells are generated by firms (and hence there maybe links between the individual price spells). Second, there is the cross-sectional distribution of ages: at a point in time, how long it has been since the current price-spell began. This is like the population census. Third, we can look at the distribution in terms of hazard rates or survival probabilities: from the cross-section of ages, the probability of progressing from one age to the next one. Lastly, we can look at the cross-section of completed price-spells (lifetimes): this corresponds to the average completed price-spell across firms and hence in this context we call it the Distribution across firms $(D A F)$. The main innovation of the paper is to develop a transparent framework that allows us to move between these concepts. The first three concepts (distribution of durations, cross-section of ages and hazard rates) are of course very well understood in statistics, being basic tools in demography, evolutionary biology and elsewhere. The fourth concept, the cross-sectional distribution of completed durations is more novel. However, this concept is essential if we are to answer questions such as what is the average price-spell across firms and to apply these concepts to understand and compare different models of pricing.

Each of these ways of looking at the class of all steady-state distributions has a natural application to modelling price and wage setting. In the Generalized Taylor Economy (GTE) (Taylor 1993, Carvalho 1995, Coenen et al 
2007 Dixon and Kara 2010), there are many sectors with different price-spell lengths, and within each sector there is a simple Taylor process. The simple Taylor economy where all contract lengths are the same is a special case of the GTE. The GTE is linked to the microdata by looking at the crosssectional $D A F$ : any cross-sectional can be represented by a unique GTE. In the Calvo approach, we have a reset probability which may be constant (as in the classical Calvo model) or duration dependent (Wolman 1999, Mash 2003 and 2004, Guerrieri 2006, Sheedy 2007, Paustian and von Hagen 2008). We show that the Calvo model with duration-dependent reset probabilities (denoted as the Generalized Calvo model $G C$ ) is linked to the microdata through the hazard function: any hazard function can be represented by a unique $G C$. Hence, both the $G T E$ and $G C$ are coextensive with the set of all steady state distributions: each possible steady state distribution has exactly one $G C$ and one $G T E$ which corresponds to it. Hence, using the framework, we are able to compare the different models of pricing for a given distribution of durations of price spells. This enables us to isolate the precise effect of the pricing model as opposed to the differences in the distribution of durations. We also explore the Multiple Calvo $(M C)$ economy: this is a multi-sector model in which each sector has a sector-specific calvo reset probability (as in Carvalho 2006, Carvalho and Nechio 2008).

The framework in this paper also allows us to directly link microdata to models of wage and price setting. We can take a given distribution of price-spells and model it as either a $G T E$ or a $G C$. We take UK CPI price data for the period 1996-2006 described in Bunn and Ellis (2009, 2010a) and estimate the hazard function from this data which we can use to calibrate a our models of pricing: the resultant GTE and GC have exactly the same distribution of price-spells as the UK data. Lastly, we take the sectoral data in Bunn and Ellis (2010a) to model the UK as an 11-sector $M C$. We are thus able to move directly from the microdata to the three models of pricing: We are able to compare these three pricing models in a simple model economy, enabling us to highlight the differences in the pricing model controlling for the distribution of price-spells. What we find is that for this distribution at least, the three pricing models are quite close in terms of the impulse-response functions they generate in response to a monetary shock. In particular, the $G C$ and $M C$ are quite similar. However, there can be differences: with the UK data we find that the GTE has a hump shaped impulse-response for inflation, whilst the $G C$ and $M C$ do not. This reflects the fact that in a GTE the firms know how long their price-spell is due to 
last and in this sense are more "myopic" in their pricing decisions.

In section 2 we review the facts about the steady state distribution of durations, ages and hazard rates. We then introduce the new concept of the cross-sectional distribution of durations across firms and show how all four concepts are related by simple formulae which are spreadsheet friendly. In section 3, we define our models of pricing and show that the $G C$ and $G T E$ are consistent with any distribution of price-spells. In section 4 we use the UK data to illustrate our ideas and how the resultant pricing models perform in a simply macroeconomy.

\section{Steady State Distributions of Durations across Firms.}

We will consider the steady-state demographics of price-spells in terms of their durations. The lifetime of a price-spell is how long it lasts from its start to its finish, a completed duration. There is a continuum agents $f$ (we will call them firms here), which set prices (or wages), represented by the unit interval $f \in[0,1]$. Time is discrete and infinite $t \in Z_{+}=\{0,1,2 \ldots \infty\}$. A price event (or price-quote) is a price set by a particular firm at a particular time: $p_{f t}$. A price spell is a duration, a sequence of consecutive periods that have the same price. For every price event pair $\{t, f\}$ we can assign an integer $d(t, f)$ which is the price spell duration of which the price event is part of. Furthermore, we can define the subset of reset price events, when firms set a new price:

$$
R=\left\{(t, f): p_{f t} \neq p_{f t-1}\right\} \subseteq[0,1] \times Z_{+}
$$

The distribution of durations is derived from the set $R$. Let the longest duration $^{1}$ be $F<\infty$. Then we can define $F$ subsets of $R$

$$
R(i)=\{(t, f) \in R: d(t, f)=i\}
$$

Thus $R(i)$ gives us the subset of durations of length $i$. The distribution of durations is simply the proportions of all durations having length $i=1 \ldots F$ :

$$
\boldsymbol{\alpha}^{d}=\left\{\alpha_{i}^{d}\right\}_{i=1}^{F} \in \Delta^{F-1}
$$

\footnotetext{
${ }^{1}$ The finiteness of $F$ is merely for convenience and has no importance since it can be set arbitrarily large.
} 
Where $\Delta^{F-1}$ is the $(F-1)$ dimensional unit simplex ${ }^{2}$. In steady-state this simplifies, since the distribution of durations of new price-spells is the same each period, we can take any "representative" $t>F$ and define

$$
\alpha_{i}^{d}=\alpha_{i}^{d}(t)=\frac{\int_{0}^{1} I((f, t) \in R(i)) d f}{\int_{0}^{1} I((f, t) \in R) d f}
$$

Where $I$ is an index function that takes the value 1 if (at our chosen $t$ ) price event $(f, t)$ is in the relevant set, 0 otherwise. In steady-state the distribution of durations is the same as the distribution of durations taken over the subset of reset prices (new price spells).

\subsection{Ages.}

The age of a price-spell at time $t$ is defined as the period of time that has elapsed since the price spell started. Formally, we can take a price event $p_{f t}$ and define the age as:

$$
\begin{aligned}
A(f, t) & =1+\min _{s}[t-s] \\
\text { s.t }(f, s) & \in R \\
s & \leq t
\end{aligned}
$$

Since we have integer time, we adopt the convention that the minimum age is 1 . Hence, for each $(t, f)$ we have an associated measure of age $a(f, t)$. Let us define the subset of firms at time $t$ that are of age $A=j$.

$$
j(t)=\{f \in[0,1]: A(f, t)=j\}
$$

Then the proportion of firms aged $j$ at $t$ is for all $t>F$

$$
\alpha_{j}^{A}=\alpha_{j}^{A}(t)=\int_{0}^{1} I((f, t) \in j(t)) . d f
$$

The steady-state distribution of ages is monotonic, since to become old you must first be young. Hence the set of all possible steady state age distributions is given by:

$$
\Delta_{M}^{F-1}=\left\{\boldsymbol{\alpha}^{A} \in \Delta^{F-1}: \alpha_{j}^{A} \geq \alpha_{j+1}^{A}\right\}
$$

where the subscript $M$ refers to (weak) monotonicity.

$$
{ }^{2} \Delta^{F-1}=\left\{\boldsymbol{\alpha} \in R_{+}^{F}: \boldsymbol{\alpha} \geq 0, \sum_{i=1}^{F} \alpha_{i}=1\right\}
$$




\subsection{Hazard Rate.}

An alternative way of looking at the steady state distribution of durations and the cross-section of ages is in terms of the hazard rate. The hazard rate at a particular age is the proportion of spells at age $i$ which do not last any longer (spells which end at age $i$, people who die at age $i$ ). Hence the hazard rate can be defined in terms of the distribution of ages in steady-state $\boldsymbol{\alpha}^{A} \in \Delta_{M}^{F-1}$ : the corresponding vector of hazard rates $^{3} h \in[0,1)^{F-1}$ (this is called the hazard function or hazard profile) is given by:

$$
h_{i}=\frac{\alpha_{i}^{A}-\alpha_{i+1}^{A}}{\alpha_{i}^{A}} ; i=1 \ldots(F-1)
$$

Corresponding to the idea of a hazard function is that of the survival probability $^{4}$, the probability at birth that the price survives for at least $i$ periods, with $S_{1}=1$ and for $i>1$

$$
S_{i}=\Pi_{\kappa=1}^{i-1}\left(1-h_{\kappa}\right)
$$

and we define the sum of survival probabilities $\Sigma_{S}$ and its reciprocal $\bar{h}$ :

$$
\Sigma_{S}=\sum_{i=1}^{F} S_{i} \quad \bar{h}=\Sigma_{S}^{-1}
$$

The survival function is the $F-1$ vector of survival probabilities $\left(S_{1}, S_{2}, \ldots S_{F}\right)$.

Clearly, we can invert (2), hence relating the age distribution to the hazard function:

Observation 1 given $h \in[0,1)^{F-1}$, there exists a unique corresponding age profile $\boldsymbol{\alpha}^{A} \in \Delta_{M}^{F-1}$ given by:

\footnotetext{
${ }^{3}$ Since the maximum length is $F$, without loss of generality we set $h_{F}=1$. Hence the hazard function is defined by the $(n-1)$ vector $\left\{h_{i}\right\}_{i=1}^{F-1}$ with $h_{i} \in[0,1)$.

${ }^{4}$ The Hazard rate can also be defined in terms of the Survival function.

$$
h_{i}=\frac{S_{i}-S_{i+1}}{S_{i}}
$$

For the relationship between continouous and discrete time used here see Kiefer (1988) and Fougere et al (2007). In continuous time,

$$
h(t)=\frac{S^{\prime}(t)}{S(t)}
$$

whilst in discrete time we take $S^{\prime}$ as $\Delta S=S_{i}-S_{i+1}$. Note that whilst in continuous time the hazard rate can be be larger than 1 , the discrete time $h_{i}$ cannot be larger than 1 .
} 


$$
\alpha_{i}^{A}=\bar{h} S_{i} \quad i=1 \ldots F .
$$

Given the flow of new contracts $\bar{h}$, the proportion surviving to age $i$ is $S_{i}: \bar{h}=\Sigma_{S}^{-1}$ ensures adding up. From the definition of hazard rates and Observation 1 we can move from an age distribution $\boldsymbol{\alpha}^{s} \in \Delta_{M}^{F-1}$ to the hazard profile and vice versa. ${ }^{5}$

Observation 2 given $h \in[0,1)^{F-1}$, there exists a unique corresponding distribution of durations $\boldsymbol{\alpha}^{d} \in \Delta^{F-1}$ given by:

$$
\alpha_{i}^{d}=S_{i} h_{i} \quad i=1 \ldots F .
$$

The proportion of price-spells of duration $i$ is the proportion surviving $i$ periods and no longer. Hence there is a unique $1-1$ relationship between elements of the set of possible duration distributions and the set of possible hazard profiles.

observation 3. For any $\boldsymbol{\alpha}^{d} \in \Delta_{M}^{F-1}$, the corresponding cross-section of ages $\boldsymbol{\alpha}^{A} \in \Delta_{M}^{F-1}$ is given by

$$
\alpha_{i}^{A}=\frac{\bar{h}}{h_{i}} \alpha_{i}^{d}
$$

and vice-versa.

\subsection{The cross-sectional distribution of Completed Price- spells across Firms.}

The steady-state age distribution $\boldsymbol{\alpha}^{A} \in \Delta_{M}^{F-1}$, distribution of durations $\boldsymbol{\alpha}^{d} \in$ $\Delta^{F-1}$ or hazard profile $h \in[0,1]^{F-1}$ are different ways of looking at the same object: a panel of price events. Each row of the panel is a trajectory of prices corresponding to a particular firm. Each column is a cross-section of all of the prices set by firms at a point in time. We now introduce a fourth distribution: it is a cross-sectional distribution of completed durations or lifetimes across firms $\boldsymbol{\alpha} \in \Delta^{F-1}$. In effect, we take a representative $t$, and

\footnotetext{
${ }^{5}$ This relationship is one of the building blocks of Life Tables (Chiang 1984), which are put to a variety of uses by demographers, actuaries and biologists. Dixon and Siciliani (2009) apply the identity to hospital waiting lists in the UK to derive the hazards and corresponding distribution of completed durations.
} 
for each firm we see the completed price-spell duration at that time $d(f, t)$. If we define

$$
R(i, t)=\{f \in[0,1]: d(t, f)=i\}
$$

then the proportion of firms at time $t$ with a completed duration of $i, \alpha_{i}$ is defined by:

$$
\alpha_{i}=\alpha_{i}(t)=\int_{0}^{1} I((f, t) \in R(i, t)) d f
$$

Under the steady-state assumption $\alpha_{i}$ is constant over time, and hence we omit the time indicator.

We can move from the distribution of ages to the distribution of completed contract lengths across firms:

Proposition 1 Consider a steady-state age distribution $\boldsymbol{\alpha}^{A} \in \Delta_{M}^{F-1}$. There exists a unique distribution of lifetimes across firms $\boldsymbol{\alpha} \in \Delta^{F-1}$ which corresponds to $\boldsymbol{\alpha}^{A}$, where

$$
\begin{aligned}
\alpha_{1}= & \alpha_{1}^{A}-\alpha_{2}^{A} \\
\alpha_{i}= & i\left(\alpha_{i}^{A}-\alpha_{i+1}^{A}\right) \\
& . \cdot \\
\alpha_{F}= & F \alpha_{F}^{A}
\end{aligned}
$$

All proofs are in the appendix. Since there is a 1-1 mapping from ages to lifetimes, we can compute the distribution of lifetimes from ages:

Corollary 1 Given a distribution of steady-state completed lifetimes across firms, $\boldsymbol{\alpha} \in \Delta^{F-1}$, there exists a unique $\boldsymbol{\alpha}^{A} \in \Delta_{M}^{F-1}$ corresponding to $\boldsymbol{\alpha}$

$$
\alpha_{j}^{A}=\sum_{i=j}^{F} \frac{\alpha_{i}}{i} \quad j=1 \ldots F
$$

The intuition behind Proposition 1 and the Corollary is clear. In a steady state, each period must look the same in terms of the distribution of ages This implies that if we look at the $i$ period price-spells, a proportion of $i^{-1}$ must be renewed each period. Thus if we have 10 period contracts, $10 \%$ of these must come up for renewal each period. This implies that the 
proportion of contracts coming up for renewal each period (which have age 1) is:

$$
\alpha_{1}^{A}=\sum_{i=1}^{\infty} \frac{\alpha_{i}}{i}
$$

The proportion of contracts aged 2 is the set of contracts that were reset last period $\left(\alpha_{1}^{s}\right)$, less the ones that only last one periods $\left(\alpha_{1}\right)$ and so on. The set of all possible steady state distributions of durations can be characterized either by the set of all possible age distributions: $\boldsymbol{\alpha}^{A} \in \Delta_{M}^{F-1}$ or the set of all possible lifetime distributions across firms $\boldsymbol{\alpha} \in \Delta^{F-1}$. They are just two different ways of looking at the same thing.

Proposition 1 and its corollary show that there is an exhaustive and 1-1 relationship between steady state age distributions and lifetime distributions. Now, since we know that there is also a 1-1 relation between Hazard rates and age distributions, we can also see that there will be a 1-1 relationship between completed contract lifetimes and hazard rates. First, we can ask what distribution of completed contract durations corresponds to a given vector of hazard rates. We can simply take observation 1 to transform the hazards into the age distribution, and then apply Proposition 1.

Corollary 2 let $h \in[0,1)^{F-1}$. The distribution of lifetimes across firms corresponding to $h$ is:

$$
\alpha_{i}=\bar{h} . i . h_{i} . S_{i}: i=1 \ldots F
$$

The flow of new contracts is $\alpha_{1}^{s}=\bar{h}$ each period. To survive for exactly $i$ periods, you have to survive to period $i$ which happens with probability $S_{i}$, and then start a new contract which happens with probability $h_{i}$. Hence from a single cohort $\bar{h} \cdot h_{i} . S_{i}$ will have contracts that last for exactly $i$ periods. We then sum over the $i$ cohorts (to include all of the contracts which are in the various stages moving towards the their final period $i$ ) to get the expression.

We can also consider the reverse question: for a given distribution of completed contract lengths $\boldsymbol{\alpha}$,what is the corresponding profile of hazard rates? From Corollary 2, note that (7) is a recursive structure relating $\alpha_{i}$ and $h_{i}: \alpha_{i}$ only depends on the values of $h_{s}$ for $s \leq i$.

Corollary 3 Consider a distribution of contract lengths across firms given by $\boldsymbol{\alpha} \in \Delta^{F-1}$. The corresponding hazard profile that will generate 
this distribution in steady state is given by $h \in[0,1)^{F-1}$ where:

$$
h_{i}=\frac{\alpha_{i}}{i}\left(\sum_{j=i}^{F} \frac{a_{j}}{j}\right)^{-1}
$$

Corollary 4. For completeness, we can also ask for a given cross-section $D A F \boldsymbol{\alpha} \in \Delta^{F-1}$, what is the corresponding distribution of durations $\boldsymbol{\alpha}^{d} \in \Delta^{F-1}$ is:

$$
\alpha_{i}^{d}=\frac{\alpha_{i}}{i . \bar{h}}
$$

This follows directly form the comparison of (7) and observation 2. Clearly, by definition, the distribution of durations is the same as the distribution across firms resetting prices (new price-spells). The more frequent price setters (shorter price-spells) have a higher representation relative to longer price-spells. Note that the rhs denominator is the product of the contract length and the proportion of firms resetting price. For the values of $i<\bar{h}^{-1}$, the share of the duration $i$ is greater across contracts than firms: for larger $i>\bar{h}^{-1}$ the share across contracts is less than the share across firms.

\section{Pricing Models with steady state distribu- tions of durations across firms.}

Having derived a unified framework for understanding the set of all possible steady state distributions of durations across firms, we can now see how this can be used to understand commonly used models of pricing behavior. Indeed, we can see how each pricing theory relates to the whole set of possible steady-state distributions. There are now several studies using micro data: in particular the Inflation Persistence Network (IPN) across the Eurozone has been particularly comprehensive ${ }^{6}$ : Alvarez and Hernando (2006) for Spain, Veronese et al (2005) for Italy, Baudry et al (2007) for France and Hoffman and Kurz-Kim (2006) for Germany. For the US we have Klenow and Krystov (2008), Nakamura and Steinsson (2008) and also Bunn and Ellis (2009, 2010) for the UK. CPI microdata is in effect a (balanced) panel on the prices of individual products sold at individual outlets. They have trajectories for

\footnotetext{
${ }^{6}$ See Dhyne et al (2006) for a summary of the IPN's findings. Alvarez (2008) also provides a useful summary.
} 
prices: sequences of price spells for a product at an individual outlet. We can think of each trajectory as analogous to the sequence of price spells for an individual firm in the context of this paper. All of these studies cover the period of the Great Moderation: there is low and stable inflation for which the assumption of steady-state is particularly appropriate: also, the studies span several years so that the seasonal variation in the data is averaged out.

The key insight is that we can use any adequate description of the whole distribution of price-spells. Under the assumption of steady-state we can then derive the others as outlined in the previous section. The way the data is usually described is the following:

1. The Hazard function. This is estimated in different ways (see Appendix 1 ), but in principle we can relate the hazard profile $\boldsymbol{h} \in[0,1)^{F-1}$ to the estimated hazard function. Most papers include the estimated hazard function for the whole economy and at a more disaggregated level. This can in principle be used to generate the corresponding distribution of durations $\left\{\alpha_{i}^{d}\right\}$ and the related cross-sectional distribution $\left\{\alpha_{i}\right\}$.

2. The frequencies of price change: $\bar{h}$. The proportion of firms changing prices per month: this can be aggregated over time or across sectors. Unfortunately, this statistic does not tell us the distribution of durations or the hazard profile. We need to make additional assumptions about the underlying distribution to unpack the distribution of durations from the frequency. In Dixon and Kara $(2005,2010)$, we assume that there is a Calvo distribution within each sector with the Calvo reset probability being the proportion of firms re-setting their price. Applying this to the Bils and Klenow (2004) data appendix, we generate the corresponding cross-sectional distribution $\left\{\alpha_{i}\right\}$.

In this section we state models of pricing that are sufficiently general to reflect the empirical micro-data on prices: these are essentially generalizations of the standard Taylor and Calvo models.

\subsection{The Generalized Taylor Economy GTE}

Using the concept of the Generalized Taylor economy GTE developed in Dixon and Kara (2005), any steady-state distribution of completed durations across firms $\boldsymbol{\alpha} \in \Delta^{F-1}$ can be represented by the GTE with the sector shares given by $\boldsymbol{\alpha} \in \Delta^{F-1}: G T E(\boldsymbol{\alpha})$. In each sector $i$ there is an $i$-period Taylor 
contract, with $i$ cohorts of equal size. The sector share is given by $\alpha_{i}$. Since the cohorts are of equal size and there as many cohorts as periods, there are $\alpha_{i} . i^{-1}$ contracts renewed each period in sector $i$. This is exactly as required in a steady-state. Hence the set of all possible GTEs is equivalent to the set of all possible steady-state distributions of durations. Note that for the $G T E$ we need to know the $D A F \boldsymbol{\alpha}$. Although we can derive the $D A F$ from the distribution of price-spells $\boldsymbol{\alpha}^{d}$, the latter cannot be applied directly to any price theory. In effect, since the distribution of durations ignores the panel structure of the economy and the role of firms in setting prices, it does not directly relate to firms pricing behavior.

In a GTE, the reset price at time $t$ in sector $i x_{i t}$ is (in log-linearised form):

$$
x_{i t}=\left(\frac{1}{\sum_{k=0}^{i-1} \beta^{k}}\right) \sum_{k=0}^{i-1} \beta^{k} p_{t+k}^{*}
$$

where $p_{t}^{*}$ is the optimal flex-price at time $t$ and $\beta$ the discount rate. There are $F$ reset price equations, with $i=1 \ldots F$. The $F$ prices in each sector $i$ are simply the average over the $i$ cohorts in that sector:

$$
p_{i t}=\frac{1}{i} \sum_{k=0}^{i-1} x_{i t-k}
$$

The aggregate price level is simply:

$$
p_{t}=\sum_{i=1}^{F} \alpha_{i} p_{i t}
$$

It is simple to verify that the age-distribution in a GTE is given by (6). If we want to know how many contracts are at aged $j$ periods, we look at sectors with lifetimes at least as large as $j, i=j \ldots F$. In each sector $i$, there is is a cohort of size $\alpha_{i} \cdot i^{-1}$ which set its price $j$ periods ago. We simply sum over all sectors $i \geq j$ to get (6). The GTE has been employed by Taylor (1993), Carvalho (1995), Coenen et al (2007), Dixon and Kara (2005, 2010), Kara $(2008,2009)^{7}$.

Note that the GTE the "sectors" $\alpha_{i}$ are defined by the duration of the price-spells, not the industry or CPI category. They are the proportion of all

\footnotetext{
${ }^{7}$ See also Whelan (2004) for a theoretcial analysis.
} 
firms (across all sectors) that have $i$ period contracts. The key thing is that when they set their price, the firm knows how long it will last ( $i$ periods). In fact, if we assume that all firms know how long the price-spells are going to last, individual firms could move between "duration sectors": for example, a firm might set a price for 3 months and be in the $i=3$ sector, and then put it on sale for one month and be in the $i=1$ sector that month and so on.

\subsection{The Generalized Calvo model $(G C)$ : duration de- pendant reset probabilities.}

The Calvo model most naturally relates to the hazard rate approach to viewing the steady state distribution of durations and it has a constant hazard rate. We now consider generalizing the Calvo model to allow for the reset probability (hazard) to vary with the age of the contract (duration dependent hazard rate). This we will denote the Generalized Calvo Model GC. A $G C$ is defined by a sequence of reset probabilities: as in the previous section this can be represented by any $\boldsymbol{h} \in[0,1)^{F-1}$ where $F$ is the shortest contract length with $h_{F}=1$. Thus the empirical hazard rates displayed in the data can be used to calibrate the hazard profile in the $G C$ model. The resultant model can be consistent with any steady-state distribution of durations, including the one found in the data ${ }^{8}$.

The $G C$ differs from the $G T E$ in that when they reset prices, firms do not know how long the price-spell is going to last. There is not a sector specific reset price, but one economy wide reset price $x_{t}$ with $x_{i t}=x_{t}$ for all $i=1 \ldots F$. The log-linearised formula for the optimal reset price at $t$ is

$$
x_{t}=\frac{1}{\sum_{k=1}^{F} S_{k} \beta^{k-1}} \sum_{k=1}^{F} S_{k} \beta^{k-1} p_{t+k-1}^{*}
$$

The aggregate price is then given by:

$$
p_{t}=\bar{h} \sum_{k=1}^{F} S_{k} x_{t-k}
$$

The difference between the $G T E$ and the $G C$ lies in the whether the duration of the price-spell is known: with the $G C$ only the distribution of price spells

\footnotetext{
${ }^{8}$ Note that an alternative parameterization of the duration dependent hazard rate model is to specify not the hazard rate at each duration, but rather the probability of the completed contract length at birth (see for example Guerrieri 2006).
} 
is known by the firm. In effect, the firm does not know ex ante which sector it is in, so that all reset-prices set at time $t$ are the same. The $G C$ model has been employed by Wolman (1999), Mash (2003,2004), Dotsey and King (2006), Guerrieri (2006), Sheedy (2007) and Paustian and von Hagen (2008).

\subsection{The Multiple Calvo Model $(M C)$.}

One format that the micro-data is presented is in the form of the proportion of firms changing prices each month, often with a detailed sectoral breakdown: see Bils and Klenow (2004), Nakamura and Steinsson (2008), Klenow and Krystov (2008), similar data in most of the IPN studies and the Bank of England work on the UK (Bunn and Ellis (2010a,b). This naturally suggests a modelling strategy of a multiple sector Calvo model $M C$. We can define a multiple Calvo process $M C$ as $M C(\tilde{\mathbf{h}}, \lambda)$ where $\tilde{h} \in(0,1)^{n}$ gives a sector specific hazard rate $^{9} \tilde{h}_{k}$ for each sector $k=1, \ldots n$ and $\boldsymbol{\lambda} \in \boldsymbol{\Delta}^{n-1}$ is the vector of shares $\lambda_{k}$ (this might be expenditure or $C P I$ weights). The reset price for each sector $k=1 \ldots n$ is then:

$$
x_{k t}=\frac{1}{\sum_{j=1}^{F}\left(1-\tilde{h}_{k}\right)^{j-1} \beta^{j-1}} \sum_{j=1}^{F}\left(1-\tilde{h}_{k}\right)^{j-1} \beta^{j-1} p_{t+j-1}^{*}
$$

The average price in each sector $k$ is then

$$
p_{k t}=\sum_{j=1}^{F}\left(1-\tilde{h}_{k}\right)^{j-1} \beta^{j-1} x_{k t-j+1}
$$

And the aggregate price is then

$$
p_{t}=\sum_{k=1}^{n} \lambda_{k} p_{k t}
$$

The Multiple Calvo model has been employed by Carvalho (2006) and Carvalho and Nechio (2008) and the earlier version of this paper (2006).

It is important to note that the $M C$ will not generally have the same hazard function as the data: it generates a smoothly declining hazard function

\footnotetext{
${ }^{9}$ The notation here should not be confused: the substrcripts $k$ are sectoral: none of the sectoral calvo reset probabiltities are duration dependent.
} 
which is different to the jagged non-monotonic hazard functions often found in the data. In that sense it is a parametric representation of the data and is not an exact representation of the data as we have in the case of the hazard or the three distributions: see Alvarez (2008).

\subsection{The Typology of Contracts.}

In terms of contract structure, we can say that the following relationships hold:

- $G C=G T E=S S$. The set of all possible steady state distributions of durations is equivalent to the set of all possible GTEs and the set of all possible $G C$ s.

- $C \subset M C \subset G C$. The set of distributions generated by the Simple Calvo is a special case of the set generated by $M C$ which is a special case of $G C$.

- $S T \subset G T E=G C$ Simple Taylor is a special case of GTE, and hence also of $G C$.

- $S T \cap M C=\varnothing$. Simple Taylor contracts are a special case of $G C$, but not of $M C$. 


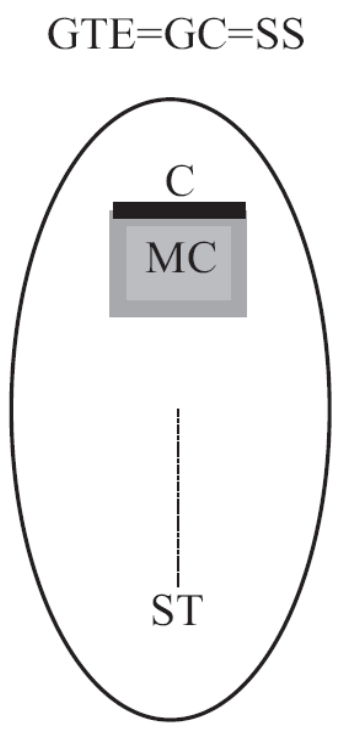

Figure 1: The

Typology Of

Contracts.

This is depicted in Fig 1. The GC and the GTE are coextensive, being the set of all possible steady-state distributions (Propositions 1 and corollary 3 ). The Simple calvo $C$ (one reset probability) is a strict subset of the Multiple Calvo process $M C$ which is a strict subset of the $G C^{10}$. The simple Taylor $S T$ and the $M C$ are disjoint. The $S T$ is a strict subset of the GTE. The size of the distributions is reflected by the Figure: $S T$ has elements corresponding to the set of integers and is represented by a few dots; Calvo is represented by the unit interval; $M C$ by the unit interval squared.

The simple Calvo and Taylor models are only applicable if there is one type of contract and no heterogeneity in the economy. If we believe the Calvo model, but that reset probabilities are heterogenous across price or wage setters, then the $M C$ makes sense. If we do not believe the Calvo model, then either the $G C$ or $G T E$ are appropriate.

\footnotetext{
${ }^{10}$ The $M C$ can be represented by a $G C$ with a decreasing Hazard. See an earlier version of the paper with the same title, ECB working paper 676, Proposition 2 for a derivation in discrete time.
} 


\section{An application to UK price data.}

In this section, I illustrate the framework of steady-state identities to the UK price data. As described in Bunn and Ellis (2009, 2010a), the ONS microdata for constructing the CPI is available for use at the VML laboratory: it covers the years 1996-2006 and consists of 11 million price-observations that were collected "locally" by ONS staff, rather than centrally. We have followed Bunn and Ellis's methodology in analyzing the data, except for the estimation of the hazard and survivor function (see Appendix 1).

Firstly, we start from the hazard function for the CPI covering all goods and services in the VML dataset: we present the Hazard for the weighted data (see Bunn and Ellis (2010a) for the weighting methodology). The weighted data puts more weight on services which have a lower hazard in the first few months. We set $F=44$ months: there are very few spells lasting more than 44 months (less than $0.01 \%)^{11}$. We depict the UK hazard rate for the first 37 months.

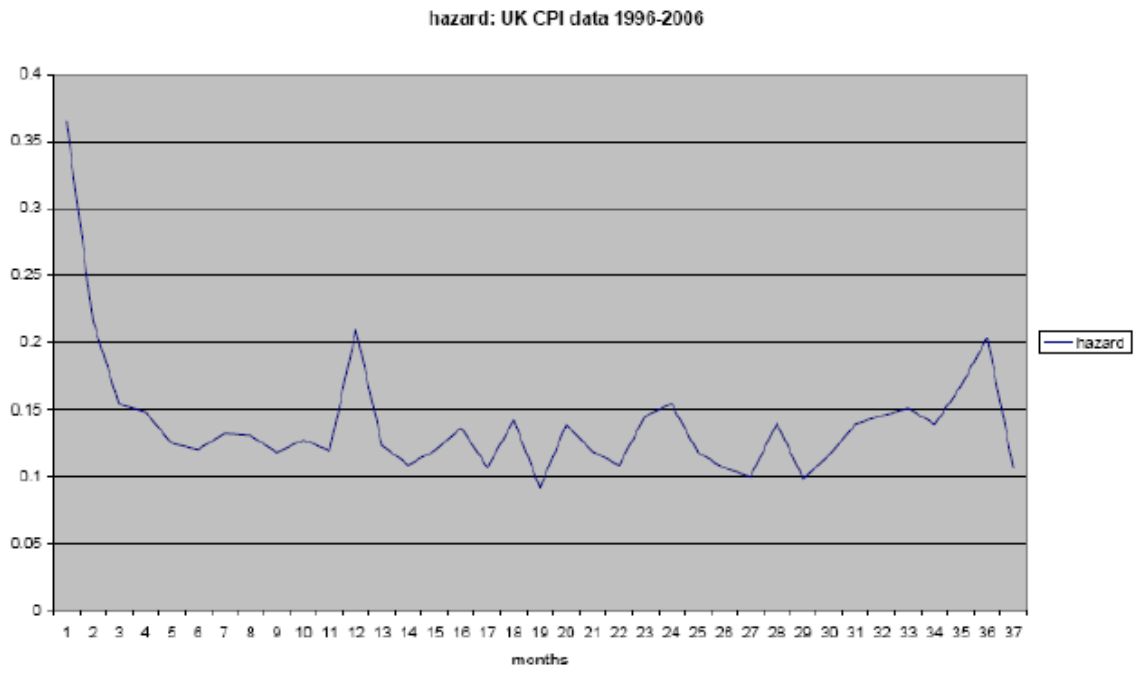

Fig 2: The UK Hazard Rate.

The CPI hazard function is similar to those found in other countries ${ }^{12}$ : it

\footnotetext{
${ }^{11} 0.086313 \%$ to be exact to 4 s.f.

${ }^{12}$ See Alvarez (2008) page 12 for examples from four EU countries.
} 
declines rapidly for the first six months: there is 12 month "spike" and after that it remains roughly constant. Note that the Hazard rate is between 10\%-15\% from month 4 onwards (except for months 12 and 24 and towards the end when very few spells survive). The implications of this are that there is a significant long-tail of price-spells. We can see this if we look at the survival function depicted in Figure 3: the probability of surviving up to 24 months is $2.4 \%$; the probability of surviving up to 36 months is a little under $0.5 \%$. The implied monthly frequency of firms re-setting their prices $\Sigma_{S}^{-1}=18.7 \%$ which is very close to the direct measurement made in Bunn and Ellis (2010a) of $19.2 \%$ in the weighted data ${ }^{13}$.

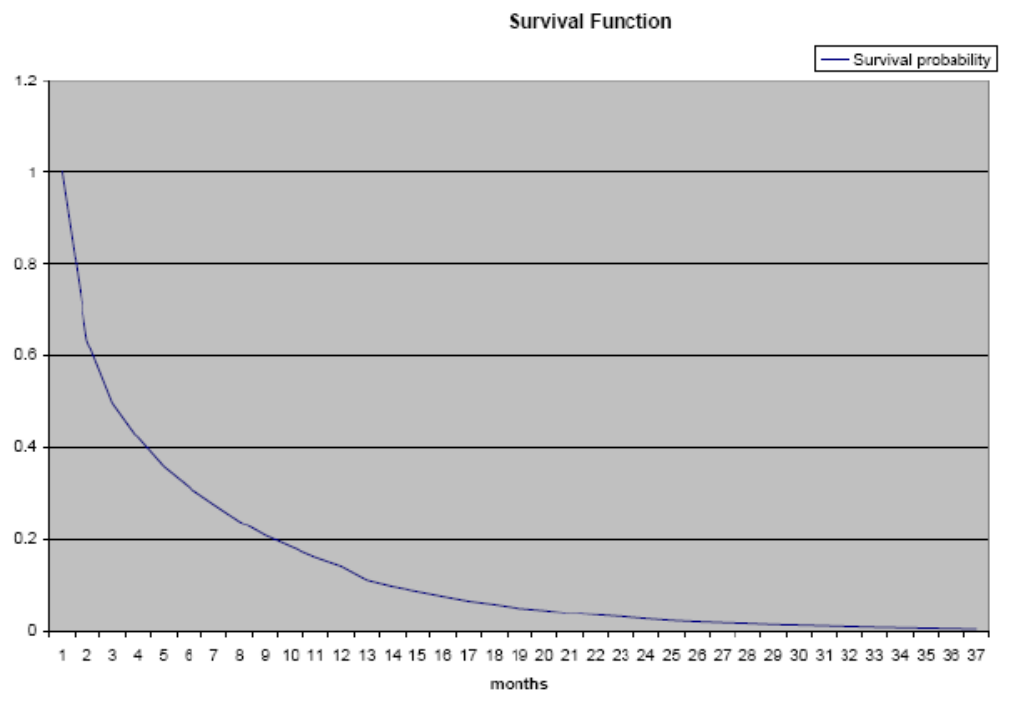

Fig 3: The UK survival function

The survival function implies that there is a very long tail in the distribution of durations and even more so in the cross-sectional DAF. As we would expect, there are a lot of short durations: $50 \%$ of price-spells last only one or two months. There is a 12 month spike, but a long tail (over $2 \%$ of price-spells last more than 24 months, $1 \%$ more than 30 months). The DAF is much flatter: the share of one and two month spells is only $12 \%$, there is a peak at 12 months and the tail is even longer and fatter: $13.4 \%$ last longer

\footnotetext{
${ }^{13}$ See Bunn and Ellis (2010a) Tables A3 and A4.
} 
than 24 months and $3 \%$ last longer than 36 months. The mean price-spell duration is $\bar{d}=5.3$ months (median 2, mode 1 ): the cross-sectional mean $\bar{T}=13.2$ months (median 10 months, mode 1 month). The cross sectional distribution is broadly consistent with the survey data (see Alvarez 2008, page 11) where firms are asked how often they change price.

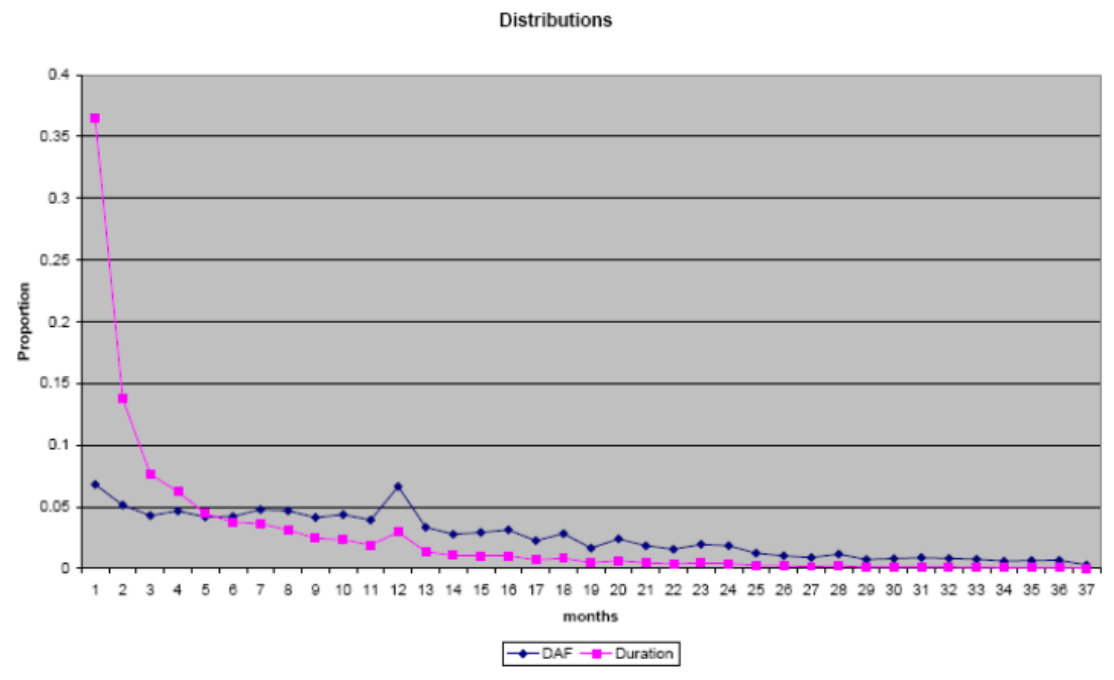

Fig 4: The UK Distributions.

An alternative way of looking at the data is parameterizing it using the Multiple Calvo $M C$ approach. In this we take data on the sectoral frequencies of price-adjustment and assume that within each sector there is a Calvo distribution. We can then sum up across sectors to obtain the aggregate distribution implied by this parameterization. By construction, this has the same frequency of price-change as in the data: 19.2\%. However, the Hazard rate is a smoothly declining one and the distribution of durations and the DAF differ significantly from the one found in the data.

\subsection{Pricing Models Compared with a UK calibration: a simple example.}

We will use the UK micro-data to see how the different models of pricing differ in terms of their impulse-response using a very simple stripped-down 
log-linearised macro-model (see Ascari 2003, Dixon and Kara 2005 and 2010). Whilst we have used an extremely simple macro-model for purposes of transparency, the pricing equations can also be set in extended DGSE models such as Smets and Wouters (2003) as is done with the French micro-data in Dixon and LeBihan (2010). The advantage of our simple model is that most of the dynamics originates from the pricing models, the only other source being a simple auto-regressive money-supply shock. To model the demand side, we use the Quantity Theory:

$$
y_{t}=m_{t}-p_{t}
$$

where $\left(p_{t}, y_{t}\right)$ are aggregate price and output and $m_{t}$ the money supply. We model the monetary process as $A R(1)$ :

$$
\begin{aligned}
m_{t} & =m_{t-1}+\varepsilon_{t} \\
\varepsilon_{t} & =\nu \varepsilon_{t-1}+\xi_{t}
\end{aligned}
$$

where $\xi_{t}$ is a white noise error term. We consider the cases of $\nu=0$ and $\nu=0.5$ (the latter follows Christiano et al (2005)).

The optimal flexible price $p_{t}^{*}$ at period $t$ in all sectors is given by:

$$
p_{t}^{*}=p_{t}+\gamma y_{t}
$$

The key parameter $\gamma$ captures the sensitivity of the flexible price to output ${ }^{14}$ : we calibrate $\gamma=0.1$ as discussed in Dixon and Kara (2010). We have converted the monthly price data into quarterly data.

Given this rudimentary macro-structure, we can then insert the sectoral reset-price equations ${ }^{15}$, and sectoral price equations into the model, and aggregate according to (11) or (16). We compare three models: the GTE, the $G C$ which both have exactly the same distribution of price-spell durations as found in the UK data, and thirdly the sectoral $M C$ model calibrated with the COICOP weights and frequencies of price-adjustment ${ }^{16}$.

\footnotetext{
${ }^{14}$ This can be due to increasing marginal cost and/or an upward sloping supply curve for labour. See for example Walsh (2003) chapter 5 and Woodford (2003) chapter 3.

${ }^{15}$ For the $G T E$ we have $(9,10)$, for the $G C$ we have $(12,13)$, for the $M C$ we have $(14,15)$.

${ }^{16}$ See Bunn and Ellis (2010a) tables A3 and A4.
} 
In Figure 5, we depict the responses of output, the reset price $^{17}$, the general price level and inflation to a one-off shock with $\gamma=0.2$. Looking at all the graphs, it is striking that the three models of pricing have fairly similar impulse-responses. However, if we compare the GTE and $G C$ (which have exactly the same distribution of price-spells), we can see that in the GTE the effect on output is consistently bigger than with the $G C E$ and likewise the effect on the price level is smaller. This can be explained by the more myopic response of the reset-prices under $G T E$ : as we can see from the mean reset-price which react less on impact for the GTE. The greater myopia of the GTE stems from the fact that if the firm knows the length of its price-spell when it sets its price, it will only take into account the flex-price over the period of the spell: it can ignore what happens after that because it knows it can re-set its price. In the $G C$ however, the firm will have to take into account events until $F$ periods hence. The resultant effect on inflation is much dampened for the GTE on impact relative to the $G C E$, the level of inflation being lower for the first 4 quarters. and higher subsequently. If we turn to the $M C$, we can see that it is similar to the $G C$ but the effect on output is larger and on the reset price and price level more sluggish. In terms of inflation, this means that there is less inflation initially (for the first six months) and more later.

In Figure 6 we consider an autoregressive monetary policy shock and find that there is now a more radical difference between the GTE and the other two models. If we look at inflation we see that there is a distinct hump shape which is exclusive to the GTE: the peak impact on inflation appears after the initial monetary shock. Whilst all IRs have a hump in output, both the $M C$ and the $G C$ have a maximum response of inflation on impact. This reflects the finding in Dixon and Kara (2010) that the Calvo model does not capture the characteristic "hump shaped" response indicated by empirical VARS. This "no hump" feature appears to be shared by its generalizations $M C$ and $G C$. If we turn to output, we can see that the effect of the monetary shock on output (prices) is consistently greater (less) in the GTE than the GCE. The $M C$ has a more ambiguous relationship. If we compare the GTE and $M C$, we can see that the average reset price and general price levels are

\footnotetext{
${ }^{17}$ The average reset price is the average conditional on the price being reset. For the GTE this is:

$$
\bar{x}_{t}=\sum_{i=1}^{F}\left(\frac{\alpha_{i}}{i}\right) x_{i t} .
$$
}



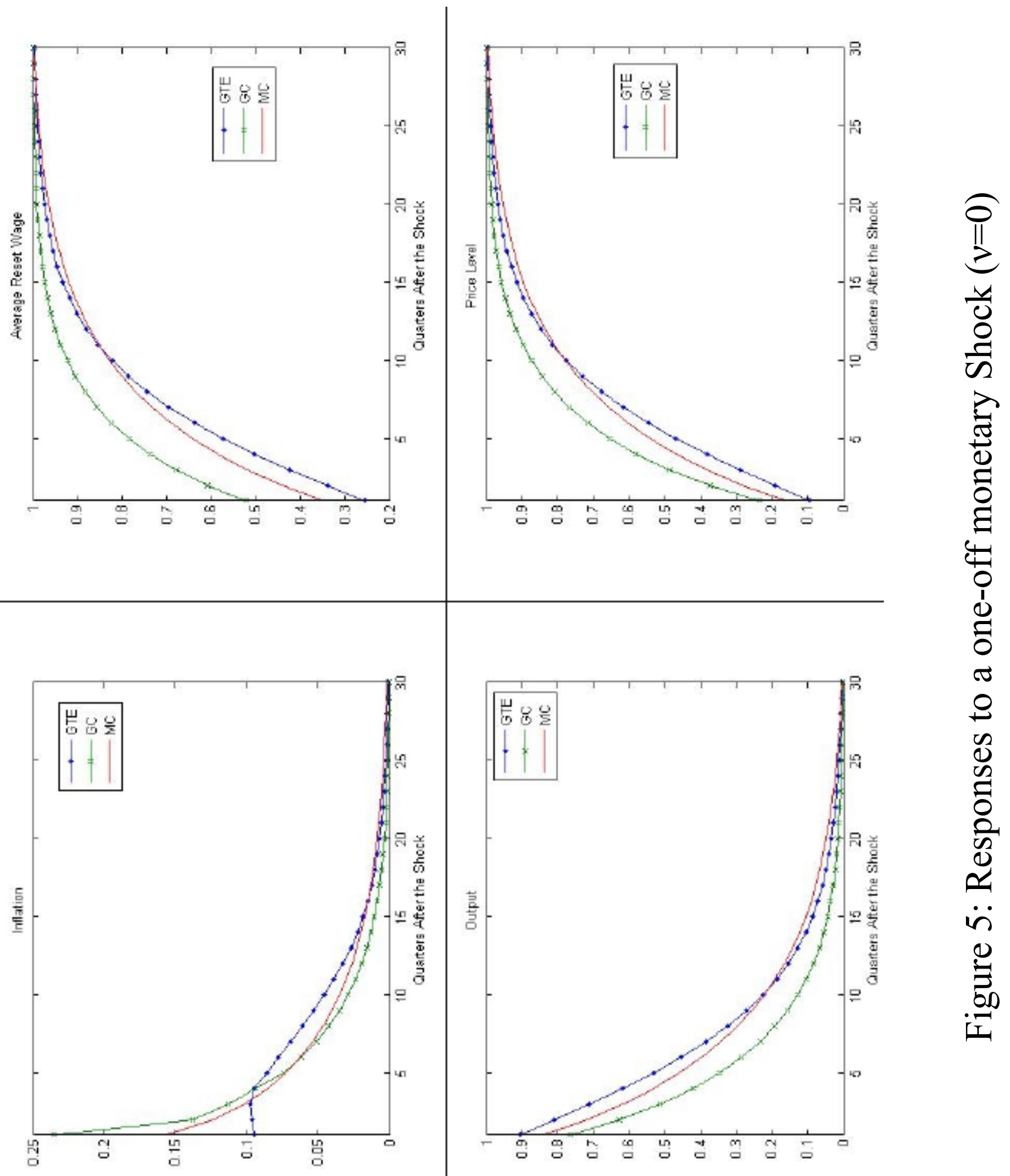


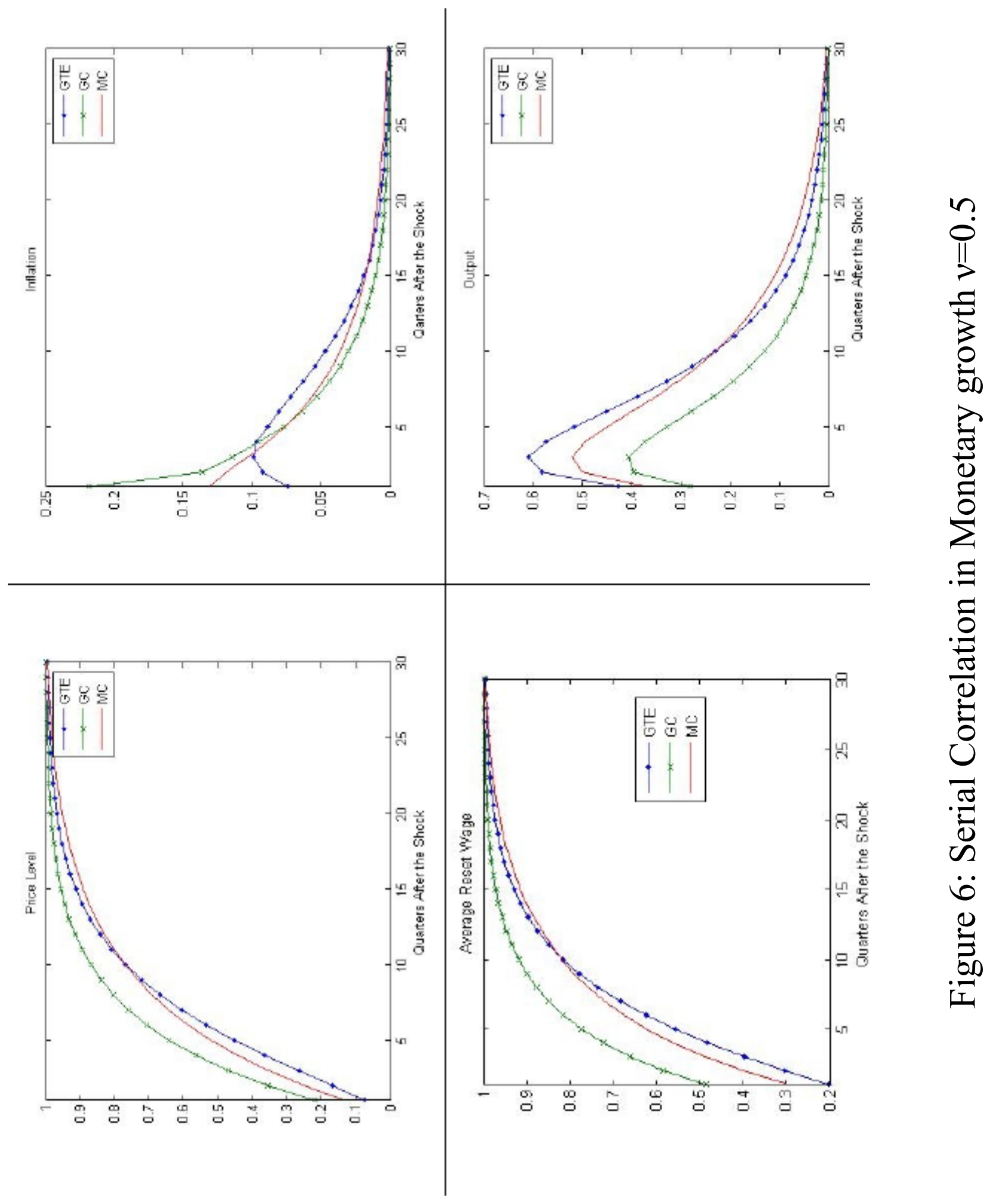


higher for the $M C$ up to the 9th quarter, and then lower: this implies that the output response is larger initially for the GTE, but less after the 10th quarter.

This example of the IRFs of major variables in a simple macro-model shows how different models of pricing can yield different patterns of behavior even though the distributions of price-spells are exactly the same or similar. This reflects differences in the pricing behaviour of firms under the different models. Using the UK data to calibrate the model, it seems to make a substantial difference to output and inflation responses depending on whether firms know the duration of their price-spells ex ante (as in the GTE) or not (as in the $G C$ ).

\section{Conclusions}

In this paper we have developed a consistent and comprehensive framework both for analyzing different pricing models (excluding the state-dependent pricing models) and relating the pricing models to the microeconomic data. In particular, the distribution of completed price-spells across firms (DAF) is a key perspective which is fundamental to understanding and comparing different models. Any steady state distribution of durations can be looked at in terms of completed durations, which suggests it can be modelled as a GTE; it can also be thought of in terms of Hazard rates which suggests the $G C$ approach. Both the $G C$ and the $G T E$ are comprehensive: they can represent all possible steady states. We also relate this approach to sectoral frequency data which is widely available and can be modelled as a $M C$. When we apply this framework to the UK micro-data, we find that the different pricing models imply different macroeconomic behaviour in terms of the impulse response functions to a monetary shock.

As more empirical micro-data becomes available, it is vital that we adopt a framework which enables us to link the data to our macroeconomic models. Whilst the approach adopted here is limited to steady-state analysis, it does provide a consistent way for linking the micro-data to the macroeconomic models of pricing. It is for future work to see how this analysis can be applied to non-steady-state analysis and state-dependent models. 


\section{Bibliography}

- Alvarez LJ, (2008), What Do Micro Price Data Tell Us on the Validity of the New Keynesian Phillips Curve?. Economics: The Open-Access, Open-Assessment E-Journal, Vol. 2, 2008-19. http://www.economicsejournal.org/economics/journalarticles/2008-19

- Alvarez, Luis and Hernando Ignacio (2006). Price setting behaviour in Spain: Stylised facts using consumer price micro data, Economic Modelling, 23, 699-716.

- Alvarez LJ, Burriel P, Hernando I (2005). Do decreasing hazard functions of price durations make any sense? ECB working paper series, No.461.

- Guido Ascari (2003), Price and Wage Staggering: a Unifying framework, Journal of Economic Surveys, 17, 511-540.

- Baharad, E. and Eden, B (2004). Price Rigidity and Price Dispersion: Evidence from micro data, Review of economic dynamics, 7, 613-641.

- Baudry L, LeBihan H, Sevestre P and Tarrieu S (2007). What do thirteen million price records have to say about consumer price rigidity? Oxford Bulletin of Economic Statistics, 69, 139-183.

- Bils, Mark and Klenow, Peter (2004). Some evidence on the importance of Sticky prices, Journal of Political Economy, 112, 947-985..

- Bunn P, Ellis C. (2009). Price setting behaviour in the UK, Bank of Englamd Quarterly Bulletin, 49, 28-36.

- Bunn P, Ellis C. (2010a) . How do individual UK consumer prices behave? Mimeo, Bank of England.

- Bunn P, Ellis C. (2010b). How do individual UK producer prices behave? Mimeo, Bank of England.

- Carvalho, Carlos V. de "Firmas Heterogeneas, Sobreposicao de Contratos e Desinflacao", Pesquisa e Planejamento Economico, V. 25 n. 3, p. 479-496, Dez. 1995 
- Carvalho, Carlos (2006) "Heterogeneity in Price Stickiness and the Real Effects of Monetary Shocks," Frontiers of Macroeconomics: Vol. 2 : Iss. 1, Article 1.

- Carvalho C and Nechio F, (2008). "Aggregation and the PPP puzzle in a sticky-price model," Staff Reports 351, Federal Reserve Bank of New York.

- Coenen G, Levin AT, Christoffel K (2007), Identifying the influences of nominal and real rigidities in aggregate price-setting behavior, Journal of Monetary Economics, 54, 2439-2466

- Chiang, C (1984). The Life Table and its Applications, Malabar, FL .Robert E Kreiger Publishing.

- Christiano L, Eichenbaum M, Evans C (2005), "Nominal Rigidities and the Dynamic Effects of a Shock to Monetary Policy", Journal of political Economy, 113, 1-45.

- Dhyne E et al (2006). Price setting in the Euro area: some stylized facts from individual consumer price data, Journal of the European Economic Association; 4, . 575-584.

- Dias D, Robalo Marques C, Santos Silva J (2007): Time or statedependent price setting rules?, European Economic Review, 51, 15891613.

- Dixon, Huw and Kara, Engin (2005): "Persistence and nominal inertia in a generalized Taylor economy: how longer contracts dominate shorter contracts", European Central Bank Working Paper 489, May 2005. Forthcoming, European Economic Review.

- Dixon, Huw and Kara, Engin (2006): "How to Compare Taylor and Calvo Contracts: A Comment on Michael Kiley", Journal of Money, Credit and Banking., 38, 1119-1126.

- Dixon Huw, Kara E (2010): Can we explain inflation persistence in a way that is consistent with the micro-evidence on nominal rigidity,. Journal of Money, Credit and Banking, 42, 151-170. 
- Dixon H and Siciliani L (2009), "Waiting Time Targets in Healthcare Markets: How Long Are We Waiting?", Journal of Health Economics, 28, 1081-1098.

- Dixon H and Le Bihan H (2010). Generalized Taylor and Generalized Calvo price and wage-setting: micro evidence with macro implications. Mimeo, Banque de France.

- Dotsey M, King R.G, and Wolman A.L. (1999): State-dependent pricing and general equilibrium dynamics of money and output, Quarterly Journal of Economics, 114(2), 655-690.

- Dotsey M, King R. (2006), Pricing, production and persistence, Journal of the European Economic Association, 4, 893-928.

- Fougère D, Le Bihan H and Sevestre P(2007) Heterogeneity in price stickiness: a microeconometric investigation, Journal of Business and Economics Statistics, 25(3), 247-264.

- Gabriel P and Reiff A. (2007) Estimating the degree of price stickiness in hungary: a hazard based approach, Mimeo, Central Bank of Hungary.

- Guerrieri, Luca, 2006. "The Inflation Persistence of Staggered Contracts," Journal of Money, Credit and Banking, 38(2), 483-494.

- John A and Wolman A, (2008). Steady-state equilibrium with statedependent pricing, Journal of Monetary Economics, 55(2), 383-405.

- Kaplan E and Meier P (1958), Non-parametric estimation from Incomplete observations, Journal of the American Statistical Association, 53, $457-481$.

- Kara E (2008) Optimal Monetary Policy in the Generalized Taylor Economy, Mimeo (revized version of ECB Working Paper No. 673) . Forthcoming Journal of Economic Dynamics and Control.

- Kara E (2009). "Input-Output Connections between sectors and Optimal Monetary Policy', National Bank of Belgium working paper no: 166.

- Keifer, N. (1988). Economic Duration Data and hazard Functions, Journal of Economic literature, 26, 646-679. 
- Klenow P and Krystov O (2008). State-Dependent vs. Time-Dependent Pricing: Does it Matter for Recent U.S. Inflation? The Quarterly Journal of Economics, 123, August 2008, 863-904.

- Mash, R (2003). New Keynesian Microfoundations Revisited: A Calvo-Taylor-Rule-of-Thumb Model and Optimal Monetary Policy Delegation, Oxford University Discussion Paper 174.

- Mash, R. (2004), "Optimising Microfoundations for Inflation Persistence", Oxford University Discussion Paper 183.

- Nakamura E and Steinsson J, 2008. "Five Facts about Prices: A Reevaluation of Menu Cost Models," The Quarterly Journal of Economics, MIT Press, vol. 123(4), pages 1415-1464, November.

- Paustian M and von Hagen J,(2008). "The Role of Contracting Schemes for Assessing the Welfare Costs of Nominal Rigidities," CEPR Discussion Papers 6726.

- Sheedy, K (2007). Intrinsic inflation persistence, CEP discussion paper 837.

- Smets F and Wouters R, (2003). An Estimated Dynamic Stochastic General Equilibrium Model of the Euro Area, Journal of the European Economic Association,1, 1123-1175, 09

- Taylor, J B (1993), Macroeconomic Policy in a World Economy, Norton.

- Veronese G, Fabiani S, Gatulli A, Sabbatini R (2005). Consumer Price behaviour in Italy: evidence from micro CPI data, ECB working paper series, No.449.

- Carl Walsh (2003) Monetary Theory and Policy (2nd edition), MIT Press.

- Whelan K (2004) Staggered price contracts and inflation persistence: some general results, ECB working paper 417.

- Wolman A (1999). Sticky prices, marginal cost and the behaviour of inflation", Federal reserve bank of Richmond quarterly, 85, 29-47. 
- Woodford M (2003) Interest and Prices: Foundations of a Theory of Monetary Policy, Princeton.university press.

\section{Appendix}

\subsection{Estimating the survival function.}

This section describes how the survival function and related hazard function in discrete time can be estimated using pricing microdata in a way that is consistent and applicable models of pricing. Currently, the methods available in the statistical packages such as SAS and STATA have been designed with other applications in mind (medical data etc) and do not give the most relevant output at first pass. They are based on the Kaplin-Meier (KM) nonparametric estimator Fortunately, it is simple to adjust the output to give the survivor and hazard functions in a manner which is consistent with the framework of this paper.

The first adjustment to the survival function required arises from the fact that we are looking at pricing models in discrete time macroeconomic framework. In these theories, the firm believes that it has a probability of 1 that it its price lasts for at least one period. The way survival rates are usually reported is that the failure occurs during the period: thus the period one survival rate is one minus the period one hazard rate. This is easily adjusted: following the pricing theory, we simply set $S(1)=1$ and then "lag" the estimated survival rates by one period to get (3). In effect, we are assuming that all of the failures in period 1 occur at the end of the period. We can see this as simply alternative ways of defining the survival rate: in standard survival analysis, $S(i)$ is the "probability of surviving to the end of period $i$ ", in this paper we define the rate as the "probability of surviving to the beginning of period $i^{\prime \prime}$.

The second issue is more complex and has to do with how we reconcile the estimated hazard function with the data on the proportion of firms changing price per month, which is $19.2 \%$ for the weighted data. From the theoretical framework of this paper, we know from (4) that the sum of the survival rates should be equal to the proportion of firms changing price each month: $\bar{h}=\Sigma_{S}^{-1}$. In order to explore this issue, we need to look more closely at how the KM estimator is implemented in packages such as SAS and STATA. First, we define the set of price-spells which we want to include (and hence 
which to exclude, such as left-censored spells). We also define an event ("failure") which in this case is a price-change. The package then looks at all the price-spells in the panel (in our paper defined by the set $R$ defined by equation (1)). It then prints out the raw data in a column: this lists the number of price-spells that lasted up to $i$ periods $i=1 \ldots F$. The first row is the total of all price-spells. The second row is those that lasted two or more periods etc. Next to this column are two others: "failed" and "lost". Of those spells that did not last more than one period, some ended because of a price-change (which we define as "failure"), and some for another reason (right truncation/censoring or some other reason). If we define the number of number of price-spells that have lasted up to the $i^{t h}$ period $n_{i}$, these are defined as the spells "at risk" of failure. Of these, $f_{i}$ fail, $L_{i}$ are lost and the rest survive to the next period: $n_{i+1}=n_{i}-f_{i}-L_{i}$. The basic KM estimator for the survival probability up to period $i$ is:

$$
\hat{S}^{1}(i)=\prod_{j=1}^{i}\left(1-\frac{f_{i}}{n_{i}}\right)
$$

A key assumption of the KM estimator is that failure and loss are mutually exclusive: that is if a spell is "lost", then it would not have failed (Kaplin and Meier (1958) page 461 describe this as "the convention that death preceeds loss").

KM recognised that this assumption would not be reasonable in many circumstances: they also considered the "adjusted-observed" estimator, which is

$$
\hat{S}^{2}(i)=\prod_{j=1}^{i}\left(1-\frac{f_{i}}{n_{i}-\frac{L_{i}}{2}}\right)
$$

This estimation method is also found in packages such as SAS and STATA. Many exisiting studies of the micro-price data appear to use either the "death preceeds loss" or the adjusted-observed estimation method: for example Bunn and Ellis (2010a,b) for the UK data, Baudry et al (2007) for the French data.

There is a basic problem with these two estimators when applied to the CPI data: the survival rates are too high. For example, with the UK data set, the implied average monthly frequency of price change (the reciprocal of the sum of survival probabilities $\Sigma_{S}^{-1}$ ) is $11 \%$, which is much smaller than what is observed in the data (19.2\%). In this paper, to remedy this problem, we have made the assumption that all of the lost spells represent failures 
("loss is failure"), so that we have:

$$
\hat{S}^{3}(i)=\prod_{j=1}^{i}\left(1-\frac{f_{i}+L_{i}}{n_{i}}\right)
$$

This estimator implies a monthly frequency of price change of $18.7 \%$ which is much closer to the data. Whilst our preferred KM estimator of the hazard function delivers a result that is closer to the data on monthly frequency of price change, it is an ad hoc improvement to the more common methodology and further research on this issue is required to develop a fully appropriate and "optimal" estimator in this context.

\subsection{Proofs.}

\subsubsection{Proof of Proposition 1 and Corollaries 1 and 3.}

Proof. The proportion of firms that have a contract that last for exactly 1 period are those that are born (age 1) and do not go on to age 2. The proportion of firms that last for exactly $i$ periods in any one cohort (born at the same time) is given by those who attain the age $i$ but who do not make it to $i+1$ : this is $\left(\alpha_{i}^{A}-\alpha_{i+1}^{A}\right)$ per cohort and at any time $t$ there are $i$ cohorts containing contracts that will last for $i$ periods.

Clearly, since $\alpha_{j}^{A}$ are monotonic, $\alpha_{i} \leq 1$, and

$$
\begin{aligned}
\sum_{i=1}^{F} \alpha_{i} & =\sum_{i=1}^{F} i\left(\alpha_{i}^{A}-\alpha_{i+1}^{A}\right) \\
& =\left(\alpha_{1}^{A}-\alpha_{2}^{A}\right)+2\left(\alpha_{2}^{A}-\alpha_{3}^{A}\right)-3\left(\alpha_{3}^{A}-\alpha_{4}^{A}\right) \ldots \\
& =\sum_{i=1}^{F} \alpha_{i}^{A}=1
\end{aligned}
$$

Hence $\boldsymbol{\alpha} \in \Delta^{F-1}$.

The relationship between the distribution of ages and lifetimes can be depicted in terms of matrix Algebra: in the case of $F=4$ :

$$
\left[\begin{array}{l}
\alpha_{1} \\
\alpha_{2} \\
\alpha_{3} \\
\alpha_{4}
\end{array}\right]=\left[\begin{array}{cccc}
1 & -1 & 0 & 0 \\
0 & 2 & -2 & 0 \\
0 & 0 & 3 & -3 \\
0 & 0 & 0 & 4
\end{array}\right]\left[\begin{array}{c}
\alpha_{1}^{A} \\
\alpha_{2}^{A} \\
\alpha_{3}^{A} \\
\alpha_{4}^{A}
\end{array}\right]
$$


Clearly, the $4 \times 4$ matrix is a mapping from $\Delta^{3} \rightarrow \Delta^{3}$ : since the matrix is of full rank, the mapping from $\alpha^{A}$ to $\alpha$ is $1-1$. Clearly, this holds for any $F$.

\subsubsection{Proof of Corollary 1:}

Proof. To see this, we can rewrite (5):

$$
\begin{aligned}
\alpha_{1} & =\alpha_{1}^{A}-\alpha_{2}^{A} \\
\frac{\alpha_{2}}{2} & =\left(\alpha_{2}^{A}-\alpha_{3}^{A}\right) \\
\frac{\alpha_{i}}{i} & =\left(\alpha_{i}^{A}-\alpha_{i+1}^{A}\right) \\
\frac{\alpha_{F}}{F} & =\alpha_{F}^{A}
\end{aligned}
$$

hence summing over all possible durations $i=1 \ldots F$ gives

$$
\sum_{i=1}^{F} \frac{\alpha_{i}}{i}=\sum_{i=1}^{F-1}\left(\alpha_{i}^{A}-\alpha_{i+1}^{A}\right)+\alpha_{F}^{A}=\alpha_{1}^{A}
$$

So that by repeated substitution we get:

$$
\begin{aligned}
& \alpha_{2}^{A}=\alpha_{1}^{A}-\alpha_{1}=\sum_{i=2}^{F} \frac{\alpha_{i}}{i} \\
& \alpha_{j}^{A}=\sum_{i=j}^{F} \frac{\alpha_{i}}{i} \quad j=1 \ldots F
\end{aligned}
$$

\subsubsection{Corollary 3.}

Proof. Rearranging the $F-1$ equations (7) we have:

$$
\frac{\alpha_{1}}{\bar{h}}=h_{1} ; \frac{\alpha_{2}}{2 \bar{h}}=h_{2}\left(1-h_{1}\right) \ldots \frac{\alpha_{i}}{i . \bar{h}}=h_{i} S_{i} ; \ldots \frac{\alpha_{F}}{F \bar{h}}=S_{F}
$$

By repeated substitution starting from $i=1$ we find that

$$
h_{i}=\frac{\alpha_{i}}{i}\left(\bar{h}-\sum_{j=1}^{i-1} \frac{\alpha_{j}}{j}\right)^{-1}
$$




$$
S_{i}=\frac{1}{\bar{h}}\left[\bar{h}-\sum_{j=1}^{i-1} \frac{\alpha_{j}}{j}\right]
$$

Since we know that $h_{F}=1$, from (20)this means that:

$$
1=\frac{\alpha_{F}}{F}\left(\bar{h}-\sum_{i=1}^{F-1} \frac{\alpha_{i}}{i}\right)^{-1} \Rightarrow \bar{h}=\sum_{i=1}^{F} \frac{\alpha_{i}}{i}
$$

Substituting the value of $\bar{h}$ into (20) establishes the result. 


\section{CESifo Working Paper Series}

for full list see www.cesifo-group.org/wp

(address: Poschingerstr. 5, 81679 Munich, Germany, office@cesifo.de)

3029 Erik Snowberg and Justin Wolfers, Explaining the Favorite-Longshot Bias: Is it RiskLove or Misperceptions?, April 2010

3030 Doina Radulescu, The Effects of a Bonus Tax on Manager Compensation and Welfare, April 2010

3031 Helmut Lütkepohl, Forecasting Nonlinear Aggregates and Aggregates with Timevarying Weights, April 2010

3032 Silvia Rocha-Akis and Ronnie Schöb, Welfare Policy in the Presence of Unionised Labour and Internationally Mobile Firms, April 2010

3033 Steven Brakman, Robert Inklaar and Charles van Marrewijk, Structural Change in OECD Comparative Advantage, April 2010

3034 Dirk Schindler and Guttorm Schjelderup, Multinationals, Minority Ownership and TaxEfficient Financing Structures, April 2010

3035 Christian Lessmann and Gunther Markwardt, Decentralization and Foreign Aid Effectiveness: Do Aid Modality and Federal Design Matter in Poverty Alleviation?, April 2010

3036 Eva Deuchert and Conny Wunsch, Evaluating Nationwide Health Interventions when Standard Before-After Doesn't Work: Malawi's ITN Distribution Program, April 2010

3037 Eric A. Hanushek and Ludger Woessmann, The Economics of International Differences in Educational Achievement, April 2010

3038 Frederick van der Ploeg, Aggressive Oil Extraction and Precautionary Saving: Coping with Volatility, April 2010

3039 Ainura Uzagalieva, Evžen Kočenda and Antonio Menezes, Technological Imitation and Innovation in New European Union Markets, April 2010

3040 Nicolas Sauter, Jan Walliser and Joachim Winter, Tax Incentives, Bequest Motives, and the Demand for Life Insurance: Evidence from two Natural Experiments in Germany, April 2010

3041 Matthias Wrede, Multinational Capital Structure and Tax Competition, April 2010

3042 Burkhard Heer and Alfred Maussner, A Note on the Computation of the Equity Premium and the Market Value of Firm Equity, April 2010

3043 Kristiina Huttunen, Jukka Pirttilä and Roope Uusitalo, The Employment Effects of Low-Wage Subsidies, May 2010 
3044 Matthias Kalkuhl and Ottmar Edenhofer, Prices vs. Quantities and the Intertemporal Dynamics of the Climate Rent, May 2010

3045 Bruno S. Frey and Lasse Steiner, Pay as you Go: A New Proposal for Museum Pricing, May 2010

3046 Henning Bohn and Charles Stuart, Population under a Cap on Greenhouse Gas Emissions, May 2010

3047 Balázs Égert and Rafal Kierzenkowski, Exports and Property Prices in France: Are they Connected?, May 2010

3048 Thomas Eichner and Thorsten Upmann, Tax-Competition with Involuntary Unemployment, May 2010

3049 Taiji Furusawa, Kazumi Hori and Ian Wooton, A Race beyond the Bottom: The Nature of Bidding for a Firm, May 2010

3050 Xavier Vives, Competition and Stability in Banking, May 2010

3051 Thomas Aronsson and Erkki Koskela, Redistributive Income Taxation under Outsourcing and Foreign Direct Investment, May 2010

3052 Michael Melvin and Duncan Shand, Active Currency Investing and Performance Benchmarks, May 2010

3053 Sören Blomquist and Laurent Simula, Marginal Deadweight Loss when the Income Tax is Nonlinear, May 2010

3054 Lukas Menkhoff, Carol L. Osler and Maik Schmeling, Limit-Order Submission Strategies under Asymmetric Information, May 2010

3055 M. Hashem Pesaran and Alexander Chudik, Econometric Analysis of High Dimensional VARs Featuring a Dominant Unit, May 2010

3056 Rabah Arezki and Frederick van der Ploeg, Do Natural Resources Depress Income Per Capita?, May 2010

3057 Joseph Plasmans and Ruslan Lukach, The Patterns of Inter-firm and Inter-industry Knowledge Flows in the Netherlands, May 2010

3058 Jenny E. Ligthart and Sebastian E. V. Werner, Has the Euro Affected the Choice of Invoicing Currency?, May 2010

3059 Håkan Selin, Marginal Tax Rates and Tax-Favoured Pension Savings of the SelfEmployed - Evidence from Sweden, May 2010

3060 Richard Cornes, Roger Hartley and Yuji Tamura, A New Approach to Solving Production-Appropriation Games with Many Heterogeneous Players, May 2010 
3061 Ronald MacDonald and Flávio Vieira, A Panel Data Investigation of Real Exchange Rate Misalignment and Growth, May 2010

3062 Thomas Eichner and Rüdiger Pethig, Efficient Management of Insecure Fossil Fuel Imports through Taxing(!) Domestic Green Energy?, May 2010

3063 Vít Bubák, Evžen Kočenda and Filip Žikeš, Volatility Transmission in Emerging European Foreign Exchange Markets, May 2010

3064 Leonid V. Azarnert, Après nous le Déluge: Fertility and the Intensity of Struggle against Immigration, May 2010

3065 William E. Becker, William H. Greene and John J. Siegfried, Do Undergraduate Majors or Ph.D. Students Affect Faculty Size?, May 2010

3066 Johannes Becker, Strategic Trade Policy through the Tax System, May 2010

3067 Omer Biran and Françoise Forges, Core-stable Rings in Auctions with Independent Private Values, May 2010

3068 Torben M. Andersen, Why do Scandinavians Work?, May 2010

3069 Andrey Launov and Klaus Wälde, Estimating Incentive and Welfare Effects of NonStationary Unemployment Benefits, May 2010

3070 Simon Gächter, Benedikt Herrmann and Christian Thöni, Culture and Cooperation, June 2010

3071 Mehmet Bac and Eren Inci, The Old-Boy Network and the Quality of Entrepreneurs, June 2010

3072 Krisztina Molnár and Sergio Santoro, Optimal Monetary Policy when Agents are Learning, June 2010

3073 Marcel Boyer and Donatella Porrini, Optimal Liability Sharing and Court Errors: An Exploratory Analysis, June 2010

3074 Guglielmo Maria Caporale, Roman Matousek and Chris Stewart, EU Banks Rating Assignments: Is there Heterogeneity between New and Old Member Countries? June 2010

3075 Assaf Razin and Efraim Sadka, Fiscal and Migration Competition, June 2010

3076 Shafik Hebous, Martin Ruf and Alfons Weichenrieder, The Effects of Taxation on the Location Decision of Multinational Firms: M\&A vs. Greenfield Investments, June 2010

3077 Alessandro Cigno, How to Deal with Covert Child Labour, and Give Children an Effective Education, in a Poor Developing Country: An Optimal Taxation Problem with Moral Hazard, June 2010 
3078 Bruno S. Frey and Lasse Steiner, World Heritage List: Does it Make Sense?, June 2010

3079 Henning Bohn, The Economic Consequences of Rising U.S. Government Debt: Privileges at Risk, June 2010

3080 Rebeca Jiménez-Rodriguez, Amalia Morales-Zumaquero and Balázs Égert, The VARying Effect of Foreign Shocks in Central and Eastern Europe, June 2010

3081 Stephane Dees, M. Hashem Pesaran, L. Vanessa Smith and Ron P. Smith, Supply, Demand and Monetary Policy Shocks in a Multi-Country New Keynesian Model, June 2010

3082 Sara Amoroso, Peter Kort, Bertrand Melenberg, Joseph Plasmans and Mark Vancauteren, Firm Level Productivity under Imperfect Competition in Output and Labor Markets, June 2010

3083 Thomas Eichner and Rüdiger Pethig, International Carbon Emissions Trading and Strategic Incentives to Subsidize Green Energy, June 2010

3084 Henri Fraisse, Labour Disputes and the Game of Legal Representation, June 2010

3085 Andrzej Baniak and Peter Grajzl, Interjurisdictional Linkages and the Scope for Interventionist Legal Harmonization, June 2010

3086 Oliver Falck and Ludger Woessmann, School Competition and Students' Entrepreneurial Intentions: International Evidence Using Historical Catholic Roots of Private Schooling, June 2010

3087 Bernd Hayo and Stefan Voigt, Determinants of Constitutional Change: Why do Countries Change their Form of Government?, June 2010

3088 Momi Dahan and Michel Strawczynski, Fiscal Rules and Composition Bias in OECD Countries, June 2010

3089 Marcel Fratzscher and Julien Reynaud, IMF Surveillance and Financial Markets - A Political Economy Analysis, June 2010

3090 Michel Beine, Elisabetta Lodigiani and Robert Vermeulen, Remittances and Financial Openness, June 2010

3091 Sebastian Kube and Christian Traxler, The Interaction of Legal and Social Norm Enforcement, June 2010

3092 Volker Grossmann, Thomas M. Steger and Timo Trimborn, Quantifying Optimal Growth Policy, June 2010

3093 Huw David Dixon, A Unified Framework for Using Micro-Data to Compare Dynamic Wage and Price Setting Models, June 2010 